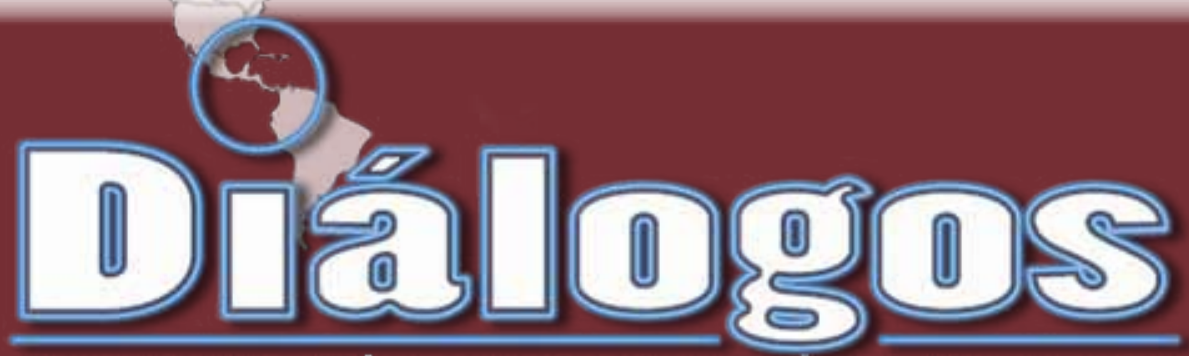

Revista Electrónica de Historia

Escuela de Historia. Universidad de Costa Rica Vol. 11 No. 1 Febrero - Setiembre 2010 ISSN 1409- 469X

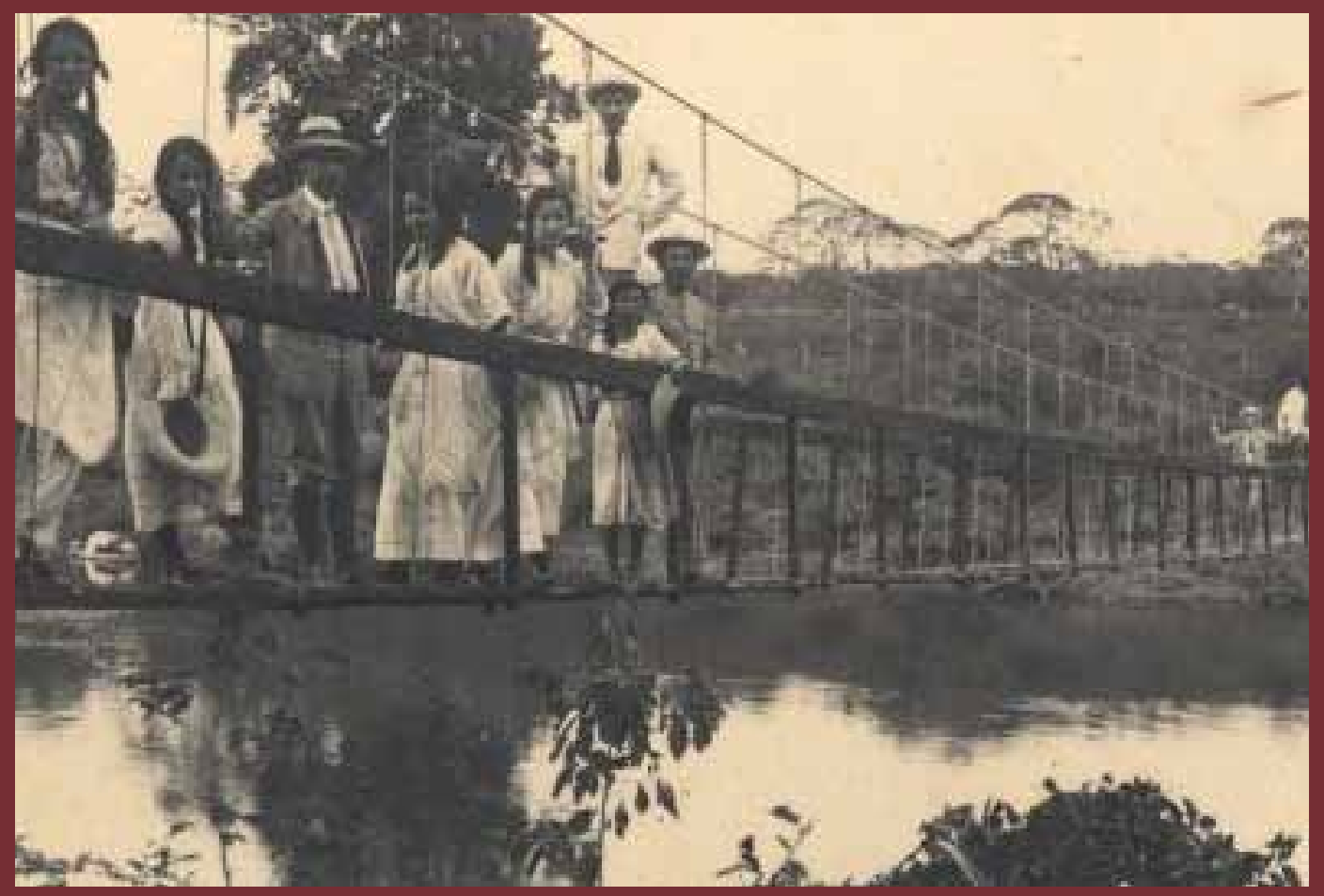

\title{
LA CAÑA DE AZÚCAR Y SUS DERIVADOS EN LA HUASTECA SAN LUÍS POTOSÍ MÉXICO
}

Noé Aguilar Rivera

Director de la Revista: Dr. Juan José Marín Hernández jmarin@fcs.ucr.ac.cr

Editor académico: Dr. Ronny Viales Hurtado ronny.viales@ucr.ac.cr

Editores técnicos: MSc. Anthony Goebel Mc Dermott goebel@racsa.co.cr

M.Sc. Marcela Quirós G. marcela.quiros@ucr.ac.cr 


\section{Miembros del Consejo Editorial:}

Dr. Ronny Viales Hurtado. Catedrático. Historia Económica y Social.Universidad de Costa Rica. ronny. viales@ucr.ac.cr

Dr. Guillermo Carvajal. Geografía Humana. Universidad de Costa Rica.

MSc. Francisco Enríquez. Historia Social. Universidad de Costa Rica.

Msc. Bernal Rivas Especialista en Archivística. Universidad de Costa Rica.

MSc. Ana Maria Botey. Historia de los movimientos sociales. Universidad de Costa Rica. abotey@gmail.com

\section{Miembros del Consejo Asesor Internacional:}

Dr. José Cal Montoya. Universidad de San Carlos de Guatemala. jecalm@correo.url.edu.gt

Dr. Juan Manuel Palacio. Universidad Nacional de San Martín. jpalacio@unsam.edu.ar

Dr. Eduardo Rey. Universidad de Santiago de Compostela. ereyt@usc.es

Dr. Heriberto Cairo Carou. Departamento de Ciencia Política y de la Administración III - Universidad Complutense de Madrid. hcairoca@cps.ucm.es

Dra. Rosa de la Fuente. Departamento de Ciencia Política y de la Administración III - Universidad Complutense de Madrid. rdelafuente@cps.ucm.es

Dr. Javier Franzé. Departamento de Ciencia Política y de la Administración III - Universidad Complutense de Madrid. javier.franze@cps.ucm.es

Dr. Jaime Preciado Coronado. japreco@hotmail.com

Dr. Gerónimo de Sierra. Vicerrector de la Universidade Federal da Integração Latino-Americana (UNILA) y Departamento de Sociología, Facultad de Ciencias Sociales de la Universidad de la República. geronimo@ fcs.edu.uy

Dr. Antonio Palazuelos. Departamento de Ciencia Política y de la Administración III - Universidad Complutense de Madrid. palazuelosa@cps.ucm.es

Dr. Werner Mackenbach. Universidad Potsdam. werner.mackenbach@uni-potsdam.de

Dr. Guillermo Castro. Ciudad del Saber Panamá. gcastro@cdspanama.org

Dra. Natalia Milanesio. University of Houston. nmilane2@Central.UH.EDU

Dr. Ricardo González Leandri. Consejo Superior de Investigaciones Cientificas - España. rgleandri@gmail. com

Dra. Mayra Espina. Centro de Estudios Psicológicos y Sociológicos, La Habana. mjdcips@ceniai.inf.cu

Dra. Montserrat Llonch. Departamento de Economía e Historia Económica Universidad Autónoma de Barcelona Montserrat.Llonch@uab.es

Dra. Estela Grassi. Universidad de Buenos Aires. estelagrassi@gmail.com 


\title{
Palabras claves
}

Caña de azúcar, Huasteca, comercio.

\section{Keywords}

Sugar cane, Huasteca, Trade.

Fecha de recepción: 15 de diciembre 2008. - Fecha de aceptación: 6 de abril 2010.

\section{Resumen}

La caña de azúcar es el principal cultivo de México, su cosecha se lleva a cabo en 665,000 ha que ocupan a 2.5 millones de personas. Existen 57 ingenios azucareros localizados en 15 estados de la republica. La industria ha cambiado dramáticamente desde la introducción de la caña de azúcar hace 486 años (año 1523) y su situación es reflejo de su metamorfosis y de intereses económicos y políticos. Fueron los españoles quienes introdujeron la caña de azúcar y tomaron así ventajas de las condiciones favorables que México ofrecía para el cultivo y la comercialización de los productos de derivados de la caña de azúcar (melazas, azúcar, panela o piloncillo y aguardiente). Grandes plantaciones fueron establecidas en diversas áreas como la Huasteca Potosina (San Luis Potosí). Esas plantaciones modificaron no solo las condiciones de vida, además la constitución de cada una de esas sociedades. El cambio fue dramático debido a la gran cantidad de indígenas nativos y al interés de los españoles hacia otras mercancías como los minerales y otros cultivos. En este trabajo se presentan algunos aspectos de la evolución y las estrategias para el desarrollo de la industria azucarera en la Huasteca Potosina San Luis Potosí durante el Virreinato de Nueva España.

\begin{abstract}
Sugar cane is the first and most important harvest in Mexico, the sugar The change was drastic because of the larger native population and the Spaniards' interest in other commodities such as minerals and other agricultural products. In this paper its present a summary of the evolution and strategies for the development of sugar industry in La Huasteca Potosina San Luis Potosi at The Viceroyalty of New Spain.
\end{abstract}

\section{Noé Aguilar Rivera}

Universidad Autónoma de San Luis Potosí Av. Sierra Leona \# 550, Col. Lomas 2 a. Sección C.P. 78210 San Luis Potosí S.L.P. México

noe.aguilar@uaslp.mx 


\section{Citado en \\ Dialnet - Latindex - \\ REDALYC- \\ Directorio y recolector \\ de recursos \\ digitales del \\ Ministerio de Cultura de España}

\section{cc) creative}

licencia de tipo

"Reconocimiento - No comercial - Compartir igual

"Diálogos Revista Electrónica de Historia" se publica interrumpidamente desde octubre de 1999.

En la cubierta: En la cubierta: Puente de don Federico Sobrado. Tempisque.

Fuente: Álbum Gira Presidencial al Guanacaste. Manuel Gómez Miralles.

Colección del Centro de Investigaciones Históricas de América Central CIHAC.

En la web. http://www.cihac.fcs.ucr.ac.cr/

Diálogos está en los siguientes repositorios:

Dialnet, http://dialnet.unirioja.es/servlet/revista?tipo_busqueda=CODIGO\&clave_revista $=3325$

Latindex http://www.latindex.unam.mx/larga.php?opcion=1\&folio=12995 ;

REDALYC http://redalyc.uaemex.mx/src/inicio/FrmBusRevs2.jsp?iEdoRev=2\&cvepai=11 ;

LANIC http://lanic.utexas.edu/la/ca/cr/indexesp.html ;

Repositorio de Revistas Universidad de Costa Rica http://www.latindex.ucr.ac.cr/

Directorio y recolector de recursos digitales del Ministerio de Cultura de España http://roai.mcu. es/es/inicio/inicio.cmd

DOJAC Directory of open access \& Hybrid journals http://www.doaj.org/doaj?func=byTitle\&hyb rid $=1 \&$ query $=\mathrm{D}$ 
http://library.georgetown.edu/newjour/d/msg02735.html

Asociación para el Fomento de los Estudios Históricos en Centroamérica

http://afehc.apinc.org/index.php?action=fi_aff\&id=1774

Universidad de Saskatchewan, Canadá

https://library.usask.ca/ejournals/view/1000000000397982

\section{Monografias}

http://www.monografias.com/Links/Historia/more12.shtml

\section{Hispanianova}

http://hispanianova.rediris.es/general/enlaces/hn0708.htm

\section{Universidad del Norte, Colombia}

http://www.uninorte.edu.co/publicaciones/memorias/enlaces.html

\section{Universidad Autónoma de Barcelona}

http://seneca.uab.es/historia/hn0708.htm

\section{Repositorio Invenia - Gestión del Conocimiento}

http:/www.invenia.es/oai:dialnet.unirioja.es:ART0000086144

\section{Enlace Académico}

http://www.enlaceacademico.org/biblioteca/revistas-en-formato-digital-centroamerica/

\section{Electronic Resources}

http://sunzi1.lib.hku.hk/ER/detail/hkul/3987318

\section{Revistas académicas en texto completo}

http://web.prw.net/ vtorres/ 


\section{LA CAÑA DE AZÚCAR Y SUS DERIVADOS EN LA HUASTECA SAN LUIIS POTOSÍ MÉXICO}

Noé Aguilar Rivera

\section{INTRODUCCIÓN}

Es un hecho generalmente aceptado que la gramínea conocida como caña de azúcar, cañadulce (Saccharum Officinarum) o cañamiel (del latín medieval canna mellis o cannamella fue conducida desde sus lugares de origen en Asia por los árabes, y especialmente en la India, a distintas parte de África y Europa, por lo regular siguiendo el rumbo de los movimientos migratorios, las invasiones y el comercio. Del Mediterráneo, el azúcar se trasladó a la Península Ibérica, dentro de la cual los reinos de Valencia y Granada se destacaron como las regiones con mayor producción ${ }^{1}$.

De forma muy parecida a otros productos agrícolas cultivados habitualmente en Europa o en las colonias africanas de los países del llamado Viejo Continente, el salto de la caña de azúcar a través del Atlántico fue un hecho en el que intervinieron navegantes, conquistadores, colonizadores y frailes procedentes de la Península Ibérica, los lusitanos llevaron la gramínea a Brasil y los hispanos a las Antillas y a otras zonas del Norte y Suramérica; así el azúcar se estaba convirtiendo en una materia prima cuyo suministro y refinamiento eran administrados cada vez mas por los poderes europeos a medida que la población comenzó a consumirla en cantidades cada vez mayores ${ }^{2}$.

A finales de 1493, cuando Colón llegó por segunda vez a América, entre una gran variedad de animales y vegetales, introdujo lo que ha sido denominado como el "más grande regalo del Viejo al Nuevo Mundo - la caña de azúcar".

La connaturalización rápida de la caña de miel con el suelo americano y la apetencia que de su dulzor sentían las huestes y pobladores hispanos $\mathrm{y}$, muy pronto, también los mismos indígenas, determinó que la gramínea se diseminara al ritmo con que se expandían las fronteras de la conquista y la formación de la "Sacarocracia" y el sistema cañamelero que impulsó el proyecto azucarero entonces tanto la difusión de la caña de azúcar como la paulatina diversificación de sus producciones derivadas (aguardiente, panela y miles) modificaron profundamente las redes de comercialización a nivel regional ${ }^{3}$. 
Desde la primera mitad del siglo XVI, cuando se iniciaron los cultivos de la caña en América, tras un largo proceso que encontró en esta geografía un espacio de protagonismo con la conquista de América. Su aprovechamiento como materia prima para la elaboración de un edulcorante de elevado contenido energético, el azúcar, se ha realizado de manera ininterrumpida y cubriendo grandes espacios a lo largo y ancho del Nuevo Continente. De igual modo, el posterior desarrollo que la agroindustria del dulce llegó a alcanzar en varios de los países del área del Caribe la convirtió en un sector determinante de sus economías nacionales, mientras que en otros desempeñó una función complementaria de suma importancia (Brasil, Colombia, Perú o México).

La producción azucarera de Nueva España de acuerdo a SánchezSantiró ${ }^{4}$ fue una de las ramas de la economía que mas se desarrollaron en los inicios del periodo colonial. Tras la producción de metales preciosos, en especial la plata, el azúcar fue la segunda mercancía en importancia. Las razones fueron varias.

Primeramente, su condición de producto de lujo. En el siglo XVI (y hasta finales del siglo XVIII) el azúcar era considerada como tal y, por 1o tanto, de alto valor unitario, 1 o cual la convertía en un producto susceptible de atraer las iniciativas productoras y mercantiles de los primeros colonizadores españoles.

En segundo lugar, la extensión del cultivo de la caña de azúcar también se vio facilitado dado que, a diferencia del trigo (alimento básico de la población española), su fabricación tuvo que hacer frente a menores controles políticos, en especial sobre los precios. Estos factores le permitieron alcanzar unos precios altísimos en los primeros anos de la colonia, 1o cual la convertía en un producto rentable para su exportación a la península. Todos estos factores confluyeron en una política virreinal que, con órdenes expresas de la monarquía española, favoreció la extensión de su cultivo y la concesión mercedes tierras para la plantación de cañaverales y la instalación de ingenios 5 .

Es decir, el sistema económico colonial novohispano quedo estructurado a partir de una producción dominante, la minería, que generaba como producto final (oro y plata) una mercancía susceptible de una inmediata realización internacional, la mercancía-dinero. En el ámbito interno, el ciclo de circulación minero determinó, en su evolución general, el espacio económico novohispano, dado que era el que acababa sosteniendo y 
fomentando la producción mercantil, la población y los consumos, es decir, el desarrollo del mercado interior colonial ${ }^{6}$

Por lo tanto, la plantación de caña de azúcar y su beneficio, al igual que otros cultivos, en las haciendas de la Nueva España y el sistema productivo basado en ellas, pueden definirse como "unidades productivas basadas en el trabajo de una mano de obra esclava o indigena, al servicio de un mercado internacional altamente competitivo y dirigidas por una permanente búsqueda de la eficiencia". Y la hacienda es "una empresa agrícola autosuficiente dedicada a la manufactura de azúcar de forma artesanal con un número limitado de esclavos y sobre la base de mano de obra indígena con un comercio regional y extraregional"; y su expansión en el territorio mexicano puede explicarse solo por haber encontrado condiciones favorables climáticas, edafológicas y ambientales en general, sino por un sostenido incremento en la demanda por parte de los colonos y el elevado precio del azúcar hasta 1600 que alentó sustancialmente el crecimiento de la producción tan solo a los tres años de la caída de Tenohctitlán así como la expansión de la minería a partir de la segunda mitad del siglo XVI en el norte de la Nueva España ${ }^{7}$. Por lo que el objetivo del presente trabajo es analizar los planteamientos de las diversas las fuentes documentales que han abordado el desarrollo de la industrialización de la caña de azúcar en la Huasteca.

\section{INTRODUCCIÓN DE LA CAÑA DE AZÚCAR EN LA HUASTECA DE SAN LUIS POTOSÍ}

En el actual estado mexicano de San Luís Potosí, región minera del norte de la Nueva España, la conquista se inició por tres puntos distintos: por la Huasteca, por el Río Verde y por la costa del Golfo. En el periodo comprendido entre 1521 y 1524, Hernán Cortés, conquistador de México, reorganizó el espacio en la denominada Huasteca potosina que estuvo condicionada por dos factores importantes: la imposición de nuevas formas de apropiación del suelo, asociadas con la irrupción de la ganadería en la planicie costera y en buena parte de la bocasierra, y la reducción de las poblaciones huastecas en congregaciones y pueblos de indios, estructuras político-territoriales formadas a finales del siglo XVI que sustituyeron a los antiguos señoríos indígenas, mediante las cuales se reubicaron los diferentes grupos étnicos y se transformaron en núcleos de asentamiento para la nueva sociedad y garantizaron la continuidad de la empresa colonizadora española. Las diversas características que adquirieron, es decir, sus atributos concretos, variaron en función de las condiciones históricas y geográficas de cada región. El ganado y los nuevos 
cultivos modificaron la estructura agraria, convirtiéndose en uno de los elementos más importantes de la dinámica social regional, por el acaparamiento de la tierra y las luchas por su recuperación en los siglos posteriores ${ }^{8}$.

La Huasteca potosina pertenece a una macroregión integrada por los estados de Hidalgo, Querétaro, Veracruz y Tamaulipas de acuerdo a una serie de criterios socioeconómicos, políticos, históricos, naturales (flora, fauna, tipo de suelos y climas semi tropicales y tropical húmedo, orografía e hidrografía). Sin embargo existen discrepancias en cuanto a la conceptualización de esta región (Figura 1); algunos estudiosos defienden la existencia de esta región, mientras que otros visualizan este concepto simplemente como una herramienta metodológica y cuestionan la veracidad de los criterios que la hacen una región?.

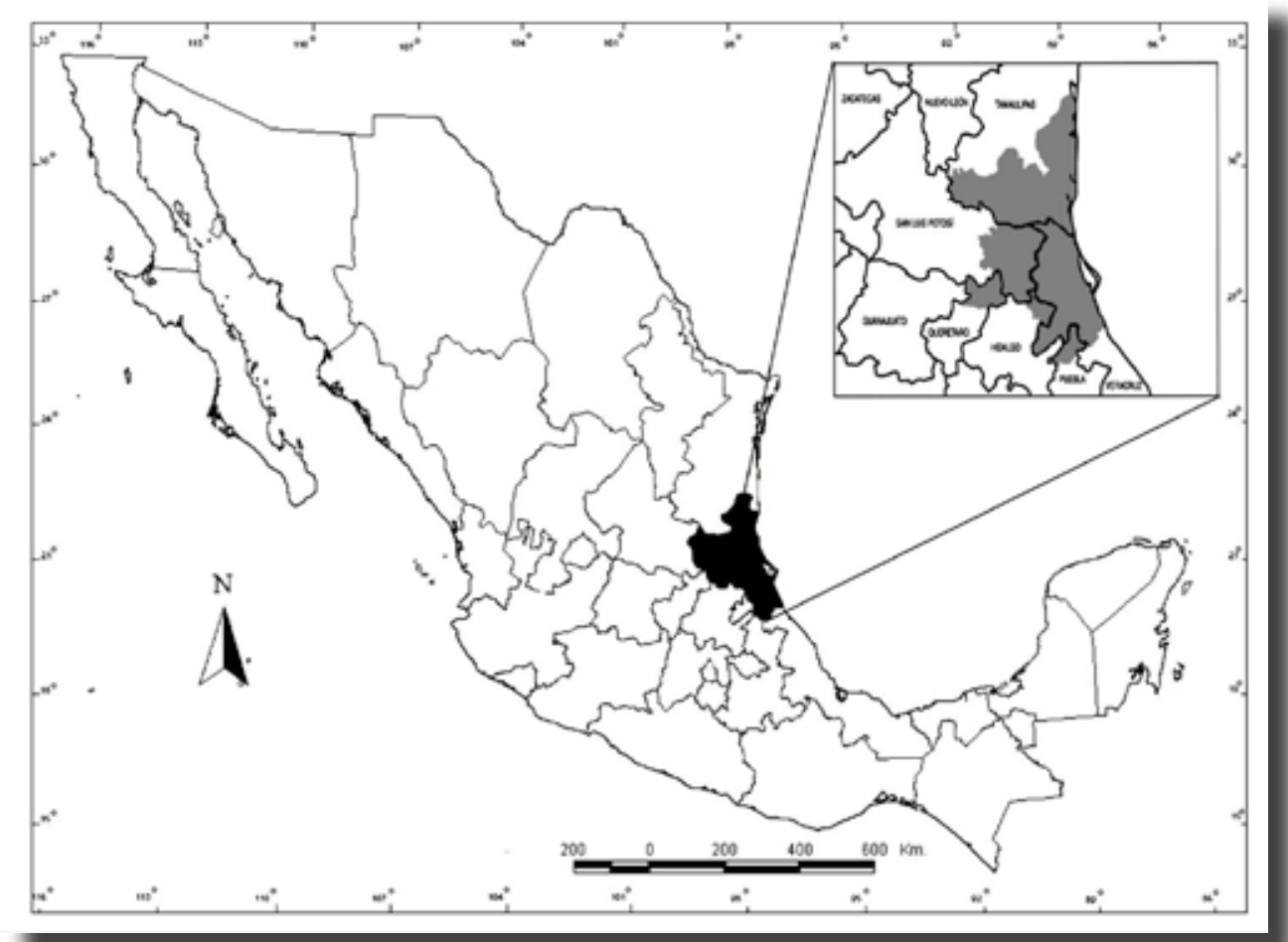

Figura 1. Ubicación de la Huasteca dentro del territorio mexicano

En el altiplano de San Luis Potosí, los españoles desarrollaron un complejo minero prototipo del centro-norte de México, pueblos mineros abastecidos por grandes haciendas ganaderas, cerealeras y azucareras y pueblos de indios tlaxcaltecas. De San Luis salían las barras de plata y oro para la Casa de moneda en México; también sebo y lana para las fábricas de Querétaro en donde eran procesados y mandados al gran mercado de México. Comerciantes de la ciudad de México tenían tiendas en los pueblos mineros de Potosí, mientras 1os 
dueños de minas y haciendas potosinas muchas veces tenían sus residencias en México. No obstante estos nexos; el complejo minero de San Luis Potosí encuadra mejor como parte integral del centro norte de México: Zacatecas, Guanajuato, Querétaro, partes de Jalisco y Durango.

Las minas de San Luis, sobre todo las del Real de Catorce mandaban su plata y oro a la Casa de Moneda en Zacatecas, los centros mineros de Guanajuato, Zacatecas y Pachuca dependían de las sales, tequezquite, sebo, azúcar y lana que les 1legaban de San Luis. Productos potosinos también abastecían las provincias de Nuevo, Coahuila. Texas y Nuevo Santander (Tamaulipas), que hasta 1822 formaban parte de la gran intendencia de San Luis Potosí. Y por los caminos reales entre San Luis Potosí, Zacatecas, Sombrerete, Durango y Guadalajara llegaban los comerciantes a la feria de San Juan de los Lagos, la feria más grande del norte a finales de la época colonial ${ }^{10}$.

Desde entonces, la Huasteca fue una zona destinada a la cría de ganado mayor; para cubrir sus necesidades de mano de obra, y las haciendas ubicadas en los valles fértiles de las partes occidental, central y sur de la Huasteca potosina combinaron la cría de ganado con el cultivo de caña de azúcar donde según Mintz ${ }^{11}$, la dulzura era lo único que unía al jugo gris verdoso de la caña (guarapo) que se chupaba de las fibras y el azúcar en sus varios tipos se usaba por los colonizadores e indigenas para endulzar el café y el chocolate.

La caña de azúcar realizó un largo recorrido, en tiempo y espacio, por el mundo hasta llegar a San Luís Potosí donde su zona cañera se destaca por su alta superficie cultivable como resultado de las diversas actividades productivas incorporadas en el territorio potosino a fines del siglo XVI y principios del siglo XVII y hasta el día de hoy y los usos de su principal derivado "el azúcar o sacarosa" se adaptaron a funciones jerárquicas y de exhibición del nivel social; la producción azucarera adoptó características distintas a las adoptadas en el resto de la Nueva España y el sector social involucrado en la misma (en numerosos casos de modo involuntario) ha padecido profundas transformaciones en su economía doméstica, su tiempo y su espacio.

Ruvalcaba $^{12}$, hace referencia que entre $1532-33$, las actividades mas comunes de los huastecos eran el comercio y la agricultura asociados entre sí, con el maíz como elemento central de su vida, economía y religión. Se sembraban y comercializaban el chile, fríjol camote, tomate, zapupe, yuca, frutales como papaya, chicozapote, anonas, piña, pitahayas y una amplia variedad de yerbas a manera de verduras, más el algodón y otros productos. Para entonces también se menciona el comercio del azúcar. El autor nuevamente hace referencia que en 1532 no queda claro si la caña se cultivaba y se procesaba en la Huasteca o si importaban el polvo dulce desde las Antillas.

Mintz ${ }^{13}$ menciona que el azúcar en ambos lados del Atlántico fue adquiriendo un significado y se asociaba con diferencias sociales de todos tipos, incluyendo 
edad, genero, clase y ocupación y se relacionaban con la voluntad y la intención de los gobernantes y con el destino económico, social y político de la metrópoli y sus periferias; así que el azúcar se vuelve mas importante para las personas en situación de esclavitud o trabajadoras como fuente de calorías y para la producción de estimulantes como el aguardiente mas que de estatus sin un proceso de imitación de las clases privilegiadas; a este tipo de uso se le denomina "extensificación" (usos ordinarios, cotidianos y esenciales). En el caso contrario "intensificación", (usos extraordinarios, ceremoniales y especialmente significativos) los que estaban en el poder son responsables tanto de la presencia de los nuevos productos como, hasta cierto grado, de sus significados, con la "extensificación" los centros de poder pueden hacerse cargo del abasto de los nuevos productos, pero los usuarios nuevos les infunden significados particulares.

El significado que alcanzo el azúcar y sus derivados en la economía europea era un asunto completamente distinto del que llego a tener en la vida de los pueblos de América, pero la disponibilidad y el precio del azúcar era consecuencia directa de las políticas imperiales que se forjaron en parte, en términos de lo que era el mercado durante la revolución del azúcar, y cada vez mas en términos de lo que podría llegar a ser. Al hacer crecer al mercado nacional, la proporción de azúcar reexportado se derrumbo bruscamente y la producción misma se afianzo de forma mas segura dentro de la orbita imperial.

A medida que se consolidaba el control sobre la producción, el consumo nacional siguió subiendo. Mucho mas tarde, cuando la política proteccionista basada en tributos e impuestos perdió competitividad ante las plantaciones inglesas de las Antillas y el proteccionismo, el azúcar en la Nueva España siguió consumiéndose en cantidades cada vez mayores ${ }^{14}$.

\section{IMPACTO DE LOS DERIVADOS DE LA CAÑA DE AZÚCAR EN LA HUASTECA}

Si el azúcar, a principios del siglo XVI, se comercializada en la Huasteca o se producía en la región, ello indicaría que, en el término de diez años, los nahuas y teenek conocieron, adoptaron y difundieron el cultivo de la caña de azúcar, y además se apropiaron de la tecnología para procesarla. De los vegetales del Viejo Mundo traídos luego de la conquista. La caña de azúcar se difundió por toda la Huasteca con una rapidez inaudita, y fueron los que gozaron de mayor estimación entre sus pobladores: para alimento y comercio. A partir de la caña se fabricaban azúcar, piloncillo y aguardiente por medio del trapiche y el alambique. El bagazo 
remanente se amontona en la bagacera, donde termina de secarse para servir de combustible en las hornallas.

La llegada de los españoles a la Huasteca y la introducción de la caña de azúcar, vino a cambiar la estructura social y cultural de los habitantes de esta zona Gallardo ${ }^{15}$. Esta simbiosis produjo en el mismo importantes transformaciones sociales y espaciales. Específicamente la instalación de los sistemas productivos representados por la plantación, la hacienda, el trapiche y el ingenio como importantes agentes en la transformación social, en especial según Sánchez-Santiró ${ }^{16}$ la propiedad sobre el agua, que en el caso de los trapiches y los ingenios es un elemento vital sin el cual no se entiende la dinámica de gran parte de los conflictos con otras haciendas en la colonia y los rublos de indios y después de la colonia con los latifundios y esto, al ser San Luís Potosí una zona donde la industria azucarera se estableció como una actividad secundaria y no primaria como la minería, han sido responsables de un quiebre en las relaciones sociales existentes entre los indígenas precolombinos residentes y la organización productivas preexistentes, en la conformación de nuevas pautas, costumbres en la economía doméstica y la vida cotidiana en los siglos posteriores.

Tierra y trabajo, los dos factores básicos de la producción azucarera colonial quedaron en manos de la hacienda. La baja intensidad en el uso del capital, es especial para la producción de piloncillo, corresponde a una pobre tecnología que, sin embargo, es superior a la que aplican las comunidades indígenas de la Huasteca; se ahorra incluso capital con el empleo extensivo de la tierra y el uso masivo de trabajo pagado a bajos salarios. El único factor que limita el crecimiento de la producción, aparte de las contingencias naturales que provocan fluctuaciones en los volúmenes de las cosechas, es el mercado, que puede definirse como extremadamente reducido, apenas de amplitud geográfica local en el caso de los bienes agrícolas de consumo básico.

La extensión del cultivo de la caña de azúcar en territorio potosino fue transformando el paisaje insular, de forma notable e irreversible debido, particularmente en el carácter deforestador de dicha expansión. Si bien el azúcar no fue "el único factor que propició la desaparición de la cubierta forestal existente a la llegada de los europeos por sus características, la economía azucarera se convirtió en la principal causa de deforestación" de la Huasteca; la Deuda Ecológica como consecuencia de la deforestación se genera en la época colonial, se intensifico con la expansión del cultivo de caña a partir de la década de 1960, como resultado de la creación de ingenios, y se sigue incrementando hasta nuestros días" a través de diferentes instrumentos, entre los cuales cabe incluir "el uso y degradación de las mejores tierras para establecer cultivos intensivos". En la medida que el auge azucarero se explica por la posibilidad de colocar el dulce en mercados regionales y del norte minero, parece claro que la expansión del cultivo de la caña para su comercio y la 
de sus derivados pudo generar en San Luis Potosi un pasivo ambiental no negligible aunque difícil de cuantificar.

De acuerdo a Crespo etal $^{17}$, en el siglo XVII la producción de azúcar en regiones diferentes a Morelos, Veracruz, Michoacán y Jalisco (Nueva Galicia) como Oaxaca, Guerrero, Reino Nuevo de León y San Luís Potosí aun no estaba definitivamente consolidada en unidades agroindustriales integradas verticalmente, sino que se practicaba el sistema de colonato que permitía que los indígenas cultivaran caña y vendieran sus cosechas a los trapiches o ingenios cercanos, a los mercados de los poblados como comestible así como leña de los montes como combustible por una parte a los grandes ingenios incorporados a las haciendas y por otra, a una extensa red de pequeños trapiches de rangos de producción muy variados que elaboraran piloncillo, panela y panocha y se destilaba aguardiente (prohibido hasta 1796).

Sin embargo, el sistema de la hacienda termino esta práctica, afianzándose dos grandes formas de la explotación azucarera que operaron independientemente y en opinión de Sanchez-Santiró ${ }^{18}$ se dio por tres razones a) el ciclo de circulación del capital minero, dada la función dominante de la minería dentro de la economía de la Nueva España, determino, en principio, la evolución de los distintos modos de producción principales existentes en las distintas regiones, b) a partir del siglo XVIII las producciones principales regionales fueron subsidiarias al capital minero que estructuro todo el conjunto de las producciones como el caso del azúcar y c) la lógica económica del proceso de expansión de la hacienda azucarera colonial implico el dominio de los recursos naturales (tierra, agua, leña, pastos) como mecanismo de control de la producción y la mano de obra y esta presión ejercida adquirió una particular aceleración en el ultimo tercio del siglo XVIII, motivada por un factor esencial: el aumento de la producción de derivados de la caña, lo cual implico el control de mas recursos naturales y el dominio de la mano de obra.

Entonces, la historia de un producto como el azúcar en una región minera como San Luís Potosí puede ofrecer materiales de interés para la comprensión del pasado y presente de distintas sociedades desde muy variadas perspectivas. El análisis del origen de la industria azucarera en esta región puede aportar elementos para conocer la relación que a través de los años tuvieron los grupos humanos con su entorno natural, el aprovechamiento de los jugos de la caña y su integración a la cultura. El conocimiento de la elaboración del azúcar, de las condiciones de trabajo y de los cambios tecnológicos que ocurrieron en el tiempo puede reflejar como ocurrió el desarrollo económico y social en determinada sociedad en relación con este ramo productivo debido a que cuando se han investigado una o varias empresas productoras de azúcar, su comercio a escala nacional o internacional o una región o nación productora con frecuencia se han encontrado respuesta a preguntas muy heterogéneas ${ }^{19}$. 
Es decir, según $\operatorname{Mint}^{20}$, antes de analizar como encuentra su lugar la caña de azúcar y sus derivados en los sistemas de alimentación o gusto de los grupos componentes o clases de una región o sociedad compleja, es necesario explicar como llego ahí (particularmente en el caso de un producto importado y que hizo importante su consumo, trasformándolo de una rareza, una novedad o una frivolidad, en una necesidad absoluta.

La hacienda en San Luís Potosí fue la unidad económica que represento en la agricultura las nuevas relaciones de producción instauradas por la Conquista en la Nueva España Interesada en la simbiosis mina-hacienda cerealera y ganadera, es un mecanismo fundamental en la extracción del excedente materializado en la plata. Juega un papel destacado en el obligado tránsito de la conquista y ocupación militar a la etapa de explotación estabilizada del nuevo país, ofreciendo a la población peninsular y a sus descendientes, los criollos, una actividad permanente y de cierta autonomía frente a los funcionarios reales, y abasteciendo de productos ibéricos a la población colonizadora que desempeñaba ocupaciones urbanas.

Todos los factores señalados configuraron y caracterizaron a los mercados de la Nueva España como eminentemente especulativos. Se vive a la caza de la oportunidad que puede brindar una mala cosecha a nivel regional para sumar ganancias respetables. Esta característica del mercado marca la lógica a que se sujeta la hacienda en la organización de los factores productivos, su administración privilegia la autosuficiencia productiva y la monopolización de los recursos productivos y de la oferta de los productos finales, medidas que son congruentes con los objetivos que persigue la unidad de producción: maximizar el excedente monetario y garantizar su sobrevivencia como unidad autónoma.

Autosuficiencia productiva y optimización del excedente monetario conducen a que la tierra que explota directamente la hacienda adopte un patrón de uso que divide en una área destinada al cultivo que se comercializa, que corresponde a un producto de mercado solvente y seguro en el que se materializa el rendimiento monetario de la hacienda; generalmente el cultivo es trigo, maíz, maguey pulquero, forrajes, etc. Otra superficie es dedicada a la siembra de maíz, cuya cosecha tiene dos posibles salidas: una segura, que es su venta al peonaje a través de esa parte del salario que se cubre en especie, precisamente de ese grano, lo que significa que la hacienda crea su propio mercado; la otra salida es coyuntural, depende de que se pueda especular con el cereal en el mercado. Una tercera área es ocupada por los forrajes que alimentan a los animales de trabajo y de carga, vale decir, las fuentes de energía biológica ${ }^{21}$.

Otra fue la situación de la hacienda azucarera que produce un artículo considerado como uno de los pocos lujos de los estratos de altos ingresos que se satisfacen con oferta interna; el mercado del azúcar es nacional, ya que en aquella época su relativamente alta densidad económica absorbe los exagerados costos de 
transporte. La amplitud del mercado dará rendimientos monetarios estables, sobre todo a las haciendas azucareras ubicadas en zonas geográficas con vocación cañera (Morelos, Veracruz, etc.) Estamos frente al ejemplo extremo de especialización en un solo producto comercializable, el azúcar, a cuya elaboración se supedita toda la organización productiva de la hacienda debido a lo que Sánchez-Santiró ${ }^{22}$ menciono: producir azúcar, piloncillo y miel implico la constitución de uno de los procesos técnicos mas complejos dentro de las distintas ramas productivas de la Nueva España. Únicamente la minería, con sus dos ámbitos de extracción y beneficio por fuego o azogue de la plata, tuvo una complejidad comparable. Como resultado de todo este complejo proceso se obtenían los siguientes productos: a) panes de azúcar (panes de azúcar blanca, entreverada blanca y mediana y prieta, b) pedaceria o polvo, c) panocha, panela o piloncillo, que era el jugo oscuro de la caña sin impurezas que se concentraba en las calderas y se vaciaba en pequeños moldes cónicos o cuadrados. Según la calidad del caldo se denominaba panocha blanca y de claros y d) miel, siendo la principal la de claros.

De esta forma la caña de azúcar se convirtió en uno de los más importantes cultivos, no sólo por la variedad de subproductos, sino por una racionalidad que va más allá de la utilizada en otros cultivos. En efecto, de la caña se utilizaba todo prácticamente, se producían diversos tipos de azúcar: baldado (blanca, entreverada, o prieta), mascabado (Sin cristalizar), espumas, espumas o postreros, panela o piloncillo entre otros.

Además en el proceso diversificado de la caña esta se cortaba, se seleccionaba la semilla, el cogollo se utiliza en la alimentación de animales, el tallo ofrecía el jugo, el bagazo se utilizaba como combustible y la ceniza como abono. Esta racionalidad explica que la caña no se conservara como cultivo de hacendados, sino que se expandiera por todo el sureste de la Nueva España, permitiendo la consolidación de sociedades campesinas que tenían caña beneficiadas en trapiches artesanales que permitían obtener las mieles necesarias para el consumo, una buena cantidad de guarapo destinada a la producción de aguardientes que eran comercializados clandestinamente, cachazas con las que alimentaran los cerdos, y cogollos y tallos para las bestias de carga y de silla. Por todo esto podríamos decir que el trapiche llegó a ser un elemento característico de las haciendas de la Nueva España. Aunque no sólo los hacendados y campesinos se beneficiaban de las rentas dejadas por la producción cañera: el Estado y la iglesia colonial hicieron de este cultivo uno de sus más importantes renglones económicos por medio del cobro del diezmo sobre la miel y el establecimiento del estanco de aguardiente ${ }^{23}$.

Sin embargo, para 1599 cuando el cultivo de caña experimentaba un gran auge conocido como el boom azucarero vinculado en la economía-mundo que los descubrimientos, la conquista y la colonización y la entrada de metales preciosos de Nueva España a Europa, debida al triunfo con los Chichimecas, permitió explotar 
metales en el Norte incrementaron el circulante en Europa y la capacidad de compra de artículos varios como el azúcar propio de la elite española y criolla, lo cual favoreció un proceso inflacionario y de expansión de la minería, las zonas cañeras y la competencia por el trabajo indígena y esclavo que fue diezmada por la peste en 1545-1548 y en 1576-1581 en zonas como Guanajuato, Zacatecas y San Luís Potosíi ${ }^{24}$.

De acuerdo a Aguilar-Robledo ${ }^{25}$ la pérdida de recursos humanos para la producción colonial, para el cristianismo y para el estado español creó una crisis en el imperio en proceso de formación. Una de las respuestas de España fue la importación de fuentes alternativas y costosas de mano de obra para remediar lo que los funcionarios europeos pensaban era una escasez inevitable de trabajadores para industrias crecientes de plata, cochinilla y azúcar. Ante este fenómeno, de falta de fuerza de trabajo, el Virrey Gaspar de Zuñiga y Acevedo Conde de Monterrey, expidió una ordenanza que limito la expansión del cultivo de caña y la instalación de trapiches e ingenios debido a que la caña disputaba los espacios destinados al maíz y el trigo y la fuerza de trabajo indígena y esclava de la minería que era empleada en los trapiches e ingenios debido a los altos precios del azúcar; esto altero la estructura productiva de la industria azucarera y ponía un violento freno a su desarrollo en pleno auge, es decir, desincentivar la inversión en este ramo. Esta medida obedeció a la necesidad de canalizar recursos hacia la producción de plata, rubro que reportaba mayores beneficios a la monarquía española. En ese tiempo se consideraba más rentable utilizar los espacios insulares del Caribe para la producción de azúcar.

Sánchez-Santiró ${ }^{26}$ planteo que esta medida no afecto la agroindustria azucarera, por el contrario, vivió un período de crecimiento entre 1600-1629 en el número de ingenios y trapiches. Un crecimiento que fue acompañado de compra de esclavos negros para el trabajo en los molinos y junto con los indígenas fueron los poblando los campos y trapiches de las nuevas haciendas, sin embargo, la ordenanza del Conde de Monterrey comenzó a profundizar una tendencia depresiva de larga duración en los precios del azúcar que iniciada en 1600 duraría hasta 1770; solo algunas zonas productoras de la Nueva España cercanas a mercados importantes lograron sobrevivir y los presentes en centro mineros como San Luís Potosí, Jalisco (Nueva Galicia) y el Nuevo Reino de León ${ }^{27}$. En este sentido, Chevalier ${ }^{28}$ menciona que se construyeron ingenios en Tamanzunchale, Villa de Valles y Tantoyuca en 1599; Bazant J. (1995) establece que la introducción formal del cultivo de la caña de azúcar en San Luís Potosí como plantación establecida fue a principios del siglo XVII por Pedro de Ochoa en Rio Verde (1621) y que coincide con el periodo de recuperación de los precios del azúcar en la Nueva España y el desplome de la minería novohispana a partir de 1630 y el descenso de importaciones de la metrópoli, lo que obligo a los 
hacendados agrícolas a una diversificación económica regional debido a los altos costos de transporte para el azúcar y los derivados de la caña del estado de Morelos y al incremento de la población consumidora en San Luis Potosi, entonces la caña de azúcar pareció adecuada no sólo para la población española sino también para la indígena, la cual rápidamente adoptó el nuevo cultivo en la región de la Huasteca, mientras las zonas central y sur permanecieron produciendo piloncillo con métodos tradicionales, el área occidental se orientó hacia la industrialización de la caña de azúcar, cambiando tanto la escala como la tecnología de producción ${ }^{29}$. Aunque hacia 1630 el gobierno virreinal reinicio la expedición de licencias para la fundación de ingenios, trapiches y plantaciones de caña pero la industria azucarera se encontraba bajo control y no podía crecer mas allá de las posibilidades que ofrecía el mercado interno.

Según Ruvalcaba ${ }^{30}$ la rápida expansión de la caña en la Huasteca a principios del siglo XVI, a diferencia de lo ocurrido en Las Antillas y otras partes de América, no tuvo relación directa con la producción de azúcar para el mercado internacional, sino con la adopción indígena de la planta, por su consumo y comercio en forma de piloncillo y aguardiente, quizás como una fuente de mieles barata. Es decir, la expansión de la caña en territorio huasteco, su cultivo, transformación y comercio, quedó en manos de los indios y no de los españoles que sólo la habían traído y también habían logrado instalar un par de ingenios dignos de llamarse como tales. Fue tal el éxito doméstico de la caña de azúcar entre los indios, que estos instalaban pequeñas fábricas de producción de piloncillo que las familias indias tenían en sus solares.

Bajo las condiciones de la expansión de la caña de azúcar en diversas regiones del mundo, la primera taza de té, chocolate o café caliente que tomo un trabajador británico o un indígena en la Nueva España o un esclavo en el Caribe hacia 1650 constituyo un acontecimiento histórico significativo, porque prefiguro la transformación de toda una sociedad, una reconfiguración total; de su base económica y social. Para la explicación de lo que significa el azúcar en una determinada región debemos esforzarnos por comprender plenamente las consecuencias de ese hecho y de otros que se relacionan con el, porque sobre ellos se erigió una concepción totalmente diferente de la relación entre productores y consumidores, del significado del trabajo, de la definición del yo, de la naturaleza de las cosas. A partir de entonces cambio para siempre la idea de lo que es un producto y de lo que significa. Y, por la misma razón, cambio concomitantemente lo que es una persona y lo que significa serlo. Al comprender la relación entre producto y persona volvemos a develar nuestra propia historia.

En fin, la cultura cañamelera de los siglos posteriores tenía un carácter industrial, entendido como la incorporación ordenada de conocimientos agronómicos 
y técnicos conducentes a obtener resultados económicos debidamente contabilizados. Y lo que era también importante, los terratenientes gozaban de una inserción clara en los centros de poder político ${ }^{31}$.

La naciente industria azucarera de San Luis Potosí tuvo necesidad de crédito para su desenvolvimiento desde épocas tempranas. A esta necesidad se sumó en la época colonial la escasez de circulante, lo que obligaba a los hacendados a recurrir a comerciantes e instituciones religiosas para obtener empréstitos en efectivo, que funcionaban como las únicas fuentes de capital líquido con que financiar el movimiento económico de la Nueva España y se generalizó el avío, que consistía en un préstamo en dinero, un adelanto de mercancías, o una combinación de ambos, destinados a salarios, víveres, insumos y reparación de maquinaria para la operación del ingenio o el cultivo de cañaverales en un ciclo productivo determinado sin embargo, su expansión estuvo condicionada por dos aspectos: a) la disposición geográfica de la creciente población dedicada a la minería a partir de su inicio en el siglo XVII, como resultado de las ordenanzas del Conde de Monterrey y su renacimiento en el siglo XVIII con la introducción de esclavos, que creaba un importante demanda interna capaz de dinamizar la actividad, fue la que determino que se estableciera en San Luís Potosí un centro regional productor de ganado, maíz, trigo y derivados de la caña; esto a su vez presentaba la debilidad de la demanda de los mercados regionales y locales y la imposibilidad de acceder a los mayores y b) San Luís Potosí presentaba la disponibilidad de nuevas tierras fértiles, menor costo de transporte a los centros de consumo regional y la fuerza de trabajo indígena y negra que condicionaron que la industria azucarera no se desarrollase en las vecinas costas del Nuevo Santander y norte de Veracruz aunque las condiciones climáticas podrían haber facilitado el cultivo de azúcar en ellas ${ }^{32}$.

Esto, por supuesto, tenía una estrecha correlación con el contexto intrarregional y la disponibilidad de tierra. Así, mientras que la "fronteriza" Huasteca norte y noreste permitió la concentración de enormes extensiones de tierra dedicadas principalmente a la ganadería extensiva; el resto de la Huasteca potosina, particularmente el sur escabroso y densamente poblado, puso importantes límites a la monopolización de la tierra y al desarrollo pecuario y favoreció el desarrollo de la caña de azúcar así tanto la geografía como la demografía condicionaron fuertemente la orientación productiva de las haciendas. Los hacendados que combinaron la cría de ganado con el cultivo de caña de azúcar, café y granos básicos, fueron los que se interesaron más en mejorar y diversificar su producción. Aunque padecieron condiciones de aislamiento, altos costos de transporte y la lejanía de los mercados, la tendencia hacia la autosuficiencia y la diversificación fue más acentuada en la parte sur de la Huasteca potosina El resultado de este proceso fue el surgimiento paulatino de rivalidades regionales, alimentadas por conflictos de intereses económicos y competencias sociales, estas fragmentaciones de lo social, político y económico, fueron a su vez favorecidas por 
las peculiaridades geográficas del territorio y por su extensión dentro del espacio del actual estado de San Luís Potosí debido a lo que González Gutiérrez ${ }^{33}$ menciono: Las regiones surgen de la interacción entre los diversos elementos de un sistema que funciona en un espacio dado. Para que esta interacción se logre debe haber flujos de gente, productos, información y decisiones, así como una red de enlaces que los permitan, además de puntos o nodos que amarren todo ello conforme a un esquema jerarquizado y dentro de un área definible; en este sentido, la diversidad es una característica esencial de las regiones: impele la relación de varios actores que intercambian bienes e información. Por ello son espacios heterogéneos, dónde los procesos se desarrollan a diferentes velocidades: los sociales tienden a moverse rápidamente, mientras que los territoriales ocurren de forma lenta y pausada.

La industrialización de la caña desde sus orígenes en el estado de San Luís Potosí es una actividad económica, pero no deja de ser un hecho geográfico y cultural; los sistemas de producción responden a las particularidades de las sociedades que los implementan en determinadas localizaciones. Así, el análisis de los procesos industriales nos lleva de uno a otro polo histórico: del social al espacial y viceversa González Gutiérrez ${ }^{34}$

La monopolización de la tierra para el cultivo de caña de azúcar en San Luís Potosí fue un proceso que trascendió el periodo colonial. Aunque con temporalidades variables, estas grandes propiedades experimentaron un proceso de consolidación y fragmentación final. Durante el proceso de fragmentación, las haciendas se convirtieron en condueñazgos, una forma dual y transitoria de tenencia de la tierra que apareció sea como propiedad heredada indivisa o como "sociedad agraria", conformada tanto por propietarios o accionistas blancos como por mestizos e indígenas. La mayoría de los condueñazgos se desintegraron más tarde en decenas de ranchos, la forma de propiedad que dominaría el escenario regional durante el siglo XX. La concentración más alta de grandes haciendas azucareras en los municipios de Valles, Tamasopo, Tamazunchale y Tampamolón debido a que eran las áreas más fértiles de la región, particularmente de las que estaban próximas a los ríos y a otros cuerpos de agua (Cuadro 1).

Para Barthas ${ }^{36}$, Las haciendas de San Luís Potosí fueron un vehículo de conquista económica, un intermediario entre la ciudad y el campo, y una forma de penetración del dominio español hacia las regiones interiores del país; vehículos reproductores de los esquemas de dominación ideológica y política forjados por el imperio español. Además, igual que sus contrapartes nacionales, las haciendas huastecas fueron focos de irradiación y reproducción del discurso de dominación español y criollo y tuvieron una fuerte orientación hacia la autosuficiencia, mediante la diversificación productiva

Durante el siglo XVII y hasta mediados del XVIII, la región se mantuvo como tierra de frontera. Asimismo, durante este periodo la población de origen hispano, 


\section{CUADRO 1. HACIENDAS AZUCARERAS, PLANTACIONES, TRAPICHES E INGENIOS EN LA}

HUASTECA POTOSINA (SIGLOS XVI-XX) ${ }^{35}$.

Nombre y Localización

Rio Verde

Tamasquin Cd. Valles

Huesco Tamazaunchale

Tampamolon

Tanlacú

Villa de los Valles

Tanchachin

Tancuayalab

Villa de los Valles

Hacienda San Dieguito Valles

Rascón

Hacienda San Ignacio del Buey

Tamasopo

Hacienda Rascón Tamasopo

Cia. Manufacturera y

Desarrolladora Rascón Tamasopo

Hacienda Gallinas Tamasopo

Hacienda Tambaca Tamasopo

Tamasopo

Ingenio Rascon Tamasopo

Tamasopo

Tamasopo Rio Sugar Co Tamasopo

The Southerm Sugar Co.Tamasopo

Hacienda Santa Isabel Tancanhuitz

Micos Valles

Hacienda El Rosario Aquismon

Hacienda Texquico Tamazunchale

Hacienda Huatepango

Tamazunchale

Hacienda San Antonio

Tamazunchale

Hacienda Huehuetlán Huehuetlán

Hacienda Huichihuayan

Huehuetlán

Hacienda Tanchachin Aquismon

Hacienda El Trigo Tamasopo

Hacienda Temalacalco Axtla

Hacienda San Francisco y Santa

Cruz Aquismon

Ingenio Agua Buena Tamasopo
Propietario

Pedro de Ochoa

Miguel Galván

Cristóbal de Larraga

Bartolomé prieto

Nicolás Ochoa

José Ochoa Jaramillo

José Rodríguez de Soria

Varios

Bernardo Lasso de la Vega

Felipe Barragán

Compañía de Jesús

Alonso de Torres

José Domingo Rascón

Familia Rascón, Alicia

Warren y Jorge E. Lee

Familia Rascón

Manuel González

Manuel Antonio Roxo

José Martín Rascon

Familia Tanner

Luís Roever

Familia Yovide

Familia Rascón

Varios

Familia Díaz

Familia Díaz

Varios

Salomón Morales

Familia Morales

Familia Ortiz

Desconocido

Desconocido

Desconocido

J.R. Roane
Fecha

1621

1638

1641

1641

1651

1674

1675

1697

1730

1790

1796

Siglo XVII

1888

1887

1887

1751

1842

1903

1923

Siglo XIX

Siglo XIX

1850

1850

1850

Siglo XVII

Siglo XIX

Siglo XIX

Siglo XX

Siglo XX

Siglo XX

Siglo XX

Siglo XX
Producción

Caña de azúcar

Trapiche

Caña de azúcar

Caña de azúcar

Trapiche

Trapiche

Trapiche

Trapiches

Plantación de caña de azúcar

Caña de azúcar y ganado vacuno

Ingenio azucarero

Caña de azúcar y ganado vacuno

Caña de azúcar y ganado vacuno

Ingenio Azucarero

Caña de Azúcar

Caña de Azúcar

Caña de Azúcar

Caña de Azúcar

Ingenio Azucarero

Ingenio Azucarero

Caña de azúcar maíz y ganado

Caña de azúcar maíz y ganado

Caña de Azúcar

Caña de azúcar y maíz

Caña de azúcar

Caña de azúcar

Piloncillo y ganado vacuno

Piloncillo y ganado vacuno

Piloncillo, café y ganado vacuno

Caña de azúcar y ganado vacuno

Caña de azúcar y maíz

Piloncillo, café y ganado vacuno

Ingenio azucarero 
indígena y mulato creciente logró consolidarse en los valles centrales. Una vez que las grandes propiedades ganaron impulso, fue muy difícil frenar su expansión. A lo largo de la Colonia existieron alrededor de 60 haciendas en la Huasteca Potosina. Aunque con temporalidades variables, estas grandes propiedades experimentaron un proceso de consolidación y fragmentación final, usurpando principalmente las tierras indígenas iniciando el proceso de indios pegujaleros ${ }^{37}$ debido a que a la altura de 1750 la esclavitud dejo de ser una relación social de producción rentable y atractiva para los hacendados azucareros, entonces según Sanchez-Santiró ${ }^{38}$ una vez que la esclavitud dejo de ser rentable para los hacendados azucareros, y estos procedieron a aumentar su producción de azúcar, piloncillo, miel y aguardiente de caña las relaciones sociales de producción imperantes fueron la gañania, el trabajo jornalero y la aparcería de tipo coercitivo extraeconómico, es decir una combinación de coerción, salario y arrendamiento.

\section{ECONOMIA DE LOS DERIVADOS DE LA CAÑA DE AZÚCAR}

Con el fin de racionalizar y mejorar la explotación del vasto imperio americano, los reyes de la nueva dinastía que gobernaba España desde los albores del siglo XVIII, se plantearon en la segunda mitad de esa centuria una remodelación, conocida habitualmente como las Reformas Borbónicas. Las medidas más importantes finales del siglo XVIII los ilustrados borbones emprendieron uno de los programas modernizadores más ambiciosos de la historia de México y en el caso del azúcar, al crecer la riqueza que aportaba a la tesorería, se iba enalteciendo su valor como articulo gravable y surgió un poderoso interés por su consumo sostenido y ampliado.

Con el modelo de funcionamiento descrito la hacienda novohispana vivió las reformas borbónicas (entre 1779 y 1789) que reactivaron la economía colonial. Apoyadas en el auge minero las haciendas ganaderas y cerealeras del norte del país incrementaron su producción. Igual cosa aconteció con las haciendas cerealeras que abastecían los centros urbanos, ahora en creciente expansión. La bonanza comprendió también a los ingenios que vieron multiplicarse el número de consumidores de azúcar ${ }^{39}$.

Se trataba de que los territorios americanos fueran mercado de las manufacturas españolas, de que se fomentara a ciertos sectores productivos, en particular la minería, para que produjeran más y pagaran más impuestos, de que se crearan monopolios estatales que proporcionaran recursos a la metrópoli y de que, en general, se gravaran, más que prohibir, diversos productos y actividades comerciales. La estrategia se llevaría a cabo mediante una reforma administrativa general que contemplaba la creación de un cuerpo de funcionarios, sin propiedad 
en el cargo, al servicio de la corona y con la tarea específica de maximizar la recaudación del Real Erario. La estrategia borbónica concebía a un Estado basado en criterios ilustrados de racionalización del ejercicio del poder, de ahí la presencia de nuevos funcionarios desligados de las clases aristócratas ${ }^{40}$

Como parte de esta política racionalizadora, se gesta un cambio de concepción de lo que es la Real Hacienda de la Nueva España; de ser una propiedad muerta que proporcionaba arriendos al rey en forma de impuestos, pasó a transformarse en un capital de la corona sujeto de ser explotado racionalmente mediante las empresas gubernamentales, la libertad del comercio y el fomento a ciertas actividades productivas así como mejor control sobre los ayuntamientos de las principales ciudades, no tanto en su función como en los componentes sociales que lo formaban al eliminar los puestos hereditarios. lo que llevaría a que se incrementara la base tributaria, que traería como consecuencia una monetarización para el pago, y por lo tanto, mayor incorporación de productos indígenas a las redes comerciales mestizoblancas, es decir, un aumento de la mercantilización; entonces el ganado (vacuno, porcino y mular), maíz, frijol, algodón (en rama y manufacturado), caña de azúcar (azucares, aguardiente y piloncillo), pero principalmente este último, fueron los productos que obtuvieron un valor susceptible de convertirse en "moneda", esto es, viendo a cada producto como instrumento de cambio, el que se integraba de esta manera a los circuitos mercantiles huastecos y extrarregionales.

De esta forma, el intercambio mercantil o libre comercio de algunos productos, como carne, ganado en pie, aguardiente y piloncillo, durante los primeros siglos coloniales en varios espacios huastecos durante los siglos XVII y XVIII provenían de diversas localidades de la costa y el Altiplano novohispano eran distribuidas y consumidas en la región, que así como la participación de indios y los que no lo eran en los circuitos mercantiles, iban más allá del espacio social conocido por ellos (ciudad de México, Chihuahua, Puebla, el Bajío y las misiones del Nuevo Santander) fueron consecuencia del decreto real de libre comercio de 1778 de acuerdo a las políticas de mercado derivadas de la naciente revolución industrial en Inglaterra ${ }^{41}$

Con respecto a este comercio que desarrollaban los indígenas en las Huastecas, la Villa de Valles estaba clasificada como de primera clase y sus mercancías eran ganado vacuno y caballar, maíz, pescado, azúcar, costalería de pita, algodón, miel de colmenas, cera, chile, tabaco y ganado menor. Pánuco y Tampico eran de segunda clase con mercancías como sal, pescado, azúcar de piloncillo, miel de caña, algodón, maíz, cera, ganado mayor, toros y cecina. El resto de las jurisdicciones de las Huastecas eran de tercera clase. De esta forma el algodón (en rama e hilado), granos, cortes de madera, azúcar de piloncillo, tabaco, chile, cera, miel, costales de pita y ganado vacuno, caracterizaban a Huauchinango. De Huejutla se 
decía que tenía azúcar de piloncillo, ganado mayor, panocha, miel, magueyes y pulque. Huayacocotla- Chicontepec tenía granos, semillas y ganado en los ranchos. Por último estarían Xochiacoatlán y Yahualica que comerciaban algodón (en rama e hilado), jabón, azúcar, sabanillas, servilletas, calcetas, medias y manteles.

Desde 1743 en el caso de Villa de Valles (Tancanhuitz), la caña de azúcar fue paulatinamente desplazando al algodón como un producto importante Básicamente eran los pueblos sureños de la jurisdicción de Villa de Valles quienes cultivaban la caña de azúcar. En Huejutla el "único" comercio que realizaban los pobladores con otras jurisdicciones cercanas, como Villa de Valles y Tampico, era gracias a la crianza de algunas cabezas de ganado y a la producción de piloncillo. La caña de azúcar fue un producto altamente cotizado, quizá más que el algodón y el ganado, pensando principalmente en los indios, ya que se cultivaba en mayor o menor medida en todos los pueblos y propiedades privadas. Los derivados de la caña de azúcar, como fueron el piloncillo y el aguardiente producto que lograron monopolizar los indígenas en términos de su producción, pero parcialmente en su comercialización y ambos productos tuvieron gran demanda en las redes comerciales Huastecas a partir de la introducción de la planta por los españoles y su persistencia a lo largo de décadas, los cultivos y la elaboración de los subproductos llegaron a tener una participación, si no destacada, al menos reconocida según Sánchez-Santiro ${ }^{42}$ en el paisaje agro artesanal de la colonia (el piloncillo los indígenas lo convertían en instrumento de cambio y en ocasiones en reales debido a que el incremento de la densidad poblacional, de la presión demográfica, genera cambios en las costumbres, en la vida social, en los procesos políticos y económicos y a su vez acusa los efectos de tales cambios).

En este contexto, la producción de derivados de la caña en La Huasteca Potosina solo pudo producirse mediante dos procesos combinados a) cambios tecnológicos y de rutinas de trabajo que aumentaron la productividad; b) obtención de las crecientes necesidades de mano de obra entre los pueblos de indios de la región, empleados como trabajadores jornaleros y genero en las siguientes décadas conflictos sociales derivados de las relaciones de producción que implicaron relaciones de poder efectivo entre las personas (esclavos, gañanes, pueblos de indios, arrendatarios) y las fuerzas productivas (agua, tierra, pastos, tecnología) además de relaciones de propiedad legal o derechos ${ }^{43}$. Y en opinión de Mintz ${ }^{44}$ la producción y comercialización de este azúcar moreno en pequeñas cantidades, vestigio de una era social y tecnológica muy temprana, continuara sin duda por tiempo indefinido a pesar de su decreciente importancia económica, al aparecer otras opciones con nuevos mercados, pues posee un sentido cultural y sentimental, tanto para los productores y consumidores.

Sharrer ${ }^{45}$, afirmo que si bien estos cambios permitieron aumentos en la producción, el proceso exigió aumentos cuantitativos en su desarrollo, al igual a 
lo que sucedió en los momentos claves de desarrollo y expansión de la industria azucarera de San Luís Potosí a partir de este momento, (principios del siglo XX, década de 1940, 1960, 1970 y 1980), en especial tierra, agua, animales de tiro y mano de obra.

En el caso del piloncillo resalta su importancia como mercancía, en la que parece que fue muy apreciado para realizar transacciones. Esto permite establecer, por lo menos para 1792, la forma en que circulaba en Villa de Valles y era comprada por individuos de distintas jurisdicciones de la Nueva España. Aunque la diferencia es sustancial no debemos olvidar que la producción de la mercancía estaba en manos de los indígenas y eran ellos los que lo hacían llegar al mercado durante la "feria del piloncillo". Por otro lado, el análisis de los grupos de mercancías derivadas de la caña de azúcar y la forma en que se presentaban, permitió conocer la base de producción a partir del paisaje natural. Esto quiere decir que se pudieron establecer criterios de cosecha, cría y manufactura a partir de la aparición mensual de los productos y da cuenta de la importancia económica de los indígenas al mercado regional esto permite esclarecer por qué ciertas localidades de la Huasteca tuvieron importancia no sólo económica, sino política y que a partir de esto se articularon territorios y espacios que, se pensaba, estaban en los límites y periferias de las transacciones mercantiles en base a los derivados de la caña de azúcar por ello, no resulta extraño que ciertas localidades, como Valle del Maíz, tuvieran extrema importancia en las transformaciones políticas de las primeras décadas del siglo XIX ${ }^{46}$.

La recuperación de la minería en el siglo XVIII incorporo dinamismo a varias actividades conexas e influía en conjunto en el proceso económico, en este sentido, la capacidad de la agricultura para satisfacer la demanda de granos básicos provoco una tendencia en el alza de los precios, además se vio favorecido por las exportaciones de azúcar de Veracruz y Morelos ocasionada por la abrupta eliminación de Haiti, principal exportador mundial de azúcar, y un ultimo acontecimiento fue la legalización del aguardiente en 1796 lo que favoreció la rentabilidad y flexibilidad de la empresas azucareras mediante la diversificación de su producción al canalizar las mieles a la elaboración de este producto ${ }^{47}$.

El estallido de la insurgencia en 1810 puso en peligro el orden social sobre el que se asentaba el dominio económico y social de los hacendados azucareros. El principal núcleo de peligro lo constituían los pueblos de indios, ya que toda la conflictividad social que hasta ese momento se había canalizado, de forma mayoritaria, vía la justicia virreynal, a través de continuos pleitos sobre expropiación de tierras, aguas, derechos de pastos podría desbordarse, como fue, en un conflicto político y militar ${ }^{48}$. Aunque la producción de la Huasteca Potosina de azúcar, piloncillo, miel y aguardiente era mínima en el conjunto de la producción agroindustrial de la Nueva 
España (por comparación a la producción de trigo, maíz y ganado) esta actividad constituía un importante negocio ya que prácticamente la totalidad se colocaba en el mercado. La independencia de México reforzó el proceso de reestructuración de la economía mexicana iniciado en el último tercio del siglo XVIII y profundizado a lo largo del periodo insurgente. Una de las facetas que sobresalen en este hecho fue el fenómeno de la regionalización económica que, llegado un punto, habría tendido a la fragmentación, en la medida que los principales nexos unificadores (en especial, la producción de plata, los circuitos de mercancías de importación, así como de determinados productos internos, caso del azúcar, el ganado y ciertas manufacturas textiles de algodón) se debilitaron dado el contexto de crisis o estancamiento económica que vivió la economía mexicana a lo largo de sus tres primeras décadas de vida independiente. En el sentido de que el fenómeno de la regionalización de la economía mexicana era el resultado de un cúmulo de factores de distinta naturaleza (políticos, fiscales, productivos, etc.), los cuales marcaban su extensión y profundidad como el caso de la agroindustria azucarera del estado de Morelos, un sector altamente mercantilizado desde el periodo colonial, generador básico de cuatro mercancías, a saber: el azúcar, el aguardiente de caña, la miel y el piloncillo/panela/panocha.

Sin embargo, La escasa producción azucarera subsistente en otras zonas del país, como San Luis Potosí, a pesar de su mejor ubicación con relación a los mercados urbanos y mineros del norte, quedó abocada a nutrir la demanda de los estados y territorios de Querétaro, Michoacán, Jalisco, Aguascalientes, Colima, Guanajuato y parte de Zacatecas durante los siglos posteriores del México independiente y existen dos razones para explicar el hecho diferencial en términos regionales y de subsector económico, a saber: la desaparición o el retroceso por casi tres décadas de competidores en la producción interna, fue el caso de las haciendas azucareras de Veracruz y Michoacán, y el establecimiento de una política arancelaria proteccionista para la agroindustria azucarera (1821) que devino prohibicionista (1824), lo cual implicó que la demanda interna de azúcar y de aguardiente de caña, quedara expedita para los productores-mercaderes del centro de México debido a tres aspectos fundamentales, en primer lugar, la continuidad en el control de la propiedad y la producción por parte de antiguas familias de hacendados-comerciantes capitalinos; en segundo lugar, el desarrollo de una extensa y densa red mercantil que abarcó hasta los mercados portuarios del Golfo de México y los reales mineros del norte $\mathrm{y}$, en tercer lugar, la existencia paralela de una red social basada en lazos familiares y de negocios que cohesionaron a dicho grupo de hacendados-comerciantes, en un contexto general de precariedad institucional ${ }^{49}$. 


\section{CONCLUSIONES}

El estudio de la caña de azúcar y sus derivados, la evolución de la tecnología azucarera y el uso de subproductos en una región determinada son una cuestión compleja por el extenso periodo que comprende y los diversos aspectos involucrados en su condición inicial de plantación, hacienda, beneficio y posteriormente agroindustria lo que refleja en la diversidad de planteamientos en las fuentes documentales. El primer punto a considerar en este trabajo fue el hecho de que la actividad azucarera fue producto de la Conquista, lo que significa que se constituyó sobre la base de la introducción de un saber tecnológico ajeno a la realidad prehispánica.

Los modelos de producción azucarera y derivados de la caña como el piloncillo, aguardiente, melazas y el impacto ambiental de los subproductos no sólo han modelado gran parte de los paisajes sociales en México (las estructuras sociales, la organización del territorio, la dinámica demográfica, las características del mercado de trabajo, etc.). También ha incidido en la cultura, entendida en su más amplia acepción, dejando marcas indelebles desde la literatura a la arquitectura, desde las ciencias sociales a las expresiones artísticas, los hábitos alimenticios y las prácticas culinarias.

La industria azucarera y piloncillera de San Luis Potosí favoreció el fenómeno de la regionalización/fragmentación de la economía en el espacio geográfico denominado "Huasteca Potosina" y fue el producto de un cúmulo de circunstancias en el que influyeron, entre otros factores, la existencia de mercados potenciales, la conformación de productores con tecnología y el desarrollo de mercancías varias derivadas de la caña de azúcar, la articulación de redes mercantiles y el papel jugado por los regímenes fiscales de la época en los distintos lugares de la geografía mexicana y generaba cuatro mercancías fundamentales, a saber: azúcar, aguardiente de caña, miel o melaza y piloncillo o panela que subsisten hasta el día de hoy a la para de la moderna agroindustria de la caña de azúcar del estado de San Luis Potosí.

\section{CITAS Y NOTAS}

1 Ramos, Gerardo. 2006. Caña de azúcar en Colombia. Revista de Indias, 2005, vol. LXV, núm. 233 49-78 pp.

2 Viña, Ana. 2006. The Social Organization of Work in Sugar Mills of the Canary Islands (15th16th centuries). En la España Medieval No. 29 359-381 pp, Abello, Alberto y Bassi, Ernesto. 2006. Un Caribe por fuera de la ruta de la Plantación, Memorias de la cátedra del Caribe Colombiano. San Andrés: Universidad Nacional de Colombia (sede Caribe) - Revista No 35 Observatorio del Caribe Colombiano, 191 pp. En: http://www.ocaribe.org/downloads/catedra_virtual/articulo_abellobassi.pdf A 
y Mintz, Sidney. 1996. Dulzura y poder, el lugar del azúcar en la historia moderna. Siglo XXI editores México D.F. 299 pp.

3 Ramos, Gerardo. 2006. Caña de azúcar en Colombia... y Abello, Alberto y Bassi, Ernesto. 2006. Un Caribe por fuera de la ruta...

4 Sánchez, Ernest. 2001. Azúcar y poder. Editorial Praxis Cuernavaca México. 331.pp

5 Von Wobeser, Gisela. 1987. La política económica de la corona española frente a la industria azucarera en la Nueva España, 1599-1630. Estudios de Historia Novohispana, Universidad Nacional Autónoma de México. Instituto de Investigaciones Históricas, Volumen 9, 51-66 pp

6 Sánchez, Ernest. 2001. Azúcar y poder...

7 Abello, Alberto y Bassi, Ernesto. 2006. Un Caribe por fuera de la ruta...

8 Moctezuma, Patricia. 2006. Los teenek productores de piloncillo. Revista Relaciones No. 106, edición primavera Vol. XXVII, 153-182 pp.

y Aguilar-Robledo Miguel. 2007. Conflictos agrarios y tenencia de la tierra en la Huasteca. Revista Relaciones Vol. XXVIII No.109, 119-154 pp.

9 Ruvalcaba, Jesús. 1996. Vacas, mulas, azúcar y café; los efectos de su introducción en la huasteca. México CIESAS.

10 Corbett, Barbara. 1989. Soberanía, elite política y espacios regionales en San Luis Potosí (1824-1828). Secuencia No. 15, septiembre-diciembre 7-27 pp.

11 Mintz, Sidney. 1996. Dulzura y poder, el lugar del ...

12 Ruvalcaba, Jesús. 1996. Vacas, mulas, azúcar y café...

13 Mintz, Sidney. 1996. Dulzura y poder, el lugar del ...

14 Viña, Ana. 2006. The Social Organization of Work in Sugar ...

15 Gallardo, Arias Patricia. 2004. Huastecos de San Luis Potosí. Pueblos indígenas del México contemporáneo. Comisión Nacional para el Desarrollo de los Pueblos Indígenas, Programa de las Naciones Unidas para el Desarrollo. Primera edición. México

16 Sánchez, Ernest. 2001. Azúcar y poder...

17 Crespo, Horacio. 1988. Historia del azúcar en México. Fondo de Cultura Económica 2 Tomos 2da edición México D.F, 1029 pp.

18 Sánchez, Ernest. 2001. Azúcar y poder...

19 Van Mentz Brigida. 1999. Notas sobre el estudio del azúcar en México, Fuentes y algunos problemas interpretativos. América Latina en la Historia Económica. No. 11 enero-junio 15-18 pp.

20 Mintz, Sidney. 1996. Dulzura y poder, el lugar del ...

21 Díaz Cerecer, Miguel Ángel. 1984. La lógica operativa de la Hacienda Mexicana. Economía, teoría y práctica. Universidad Autónoma Metropolitana México, número 5, 89 pp.

22 Sánchez, Ernest. 2001...

23 Viña, Ana. 2006. The Social Organization of Work in Sugar ...

24 Von Wobeser, Gisela. 1987. La política económica de la corona...

25 Aguilar-Robledo Miguel. 1998. Haciendas y condueñazgos en la Huasteca potosina. En: nuevos aportes al conocimiento de la Huasteca. Centro de Investigaciones y Estudios Superiores en Antropología Social CIESAS, México 388 pp.

26 Sánchez, Ernest. 2001. Azúcar y poder...

27 Crespo, Horacio. 1988. Historia del azúcar en México....

28 Chevalier François. 1999. La formación de los latifundios en México, hacienda y sociedad en los siglos XVI, XVII y XVIII. Fondo de Cultura Económica 2da edición, 648 pp.

29 Von Wobeser, Gisela. 1987. La política económica de la corona...

30 Ruvalcaba, Jesús. 1996. Vacas, mulas, azúcar y café

31 Mintz, Sidney. 1996. Dulzura y poder, el lugar del ... 
32 Crespo, Horacio. 1988. Historia del azúcar en México.... y Von Wobeser, Gisela. 1987. La política económica de la corona...

33 González Gutiérrez, Darío. 2006. La industrialización como detonante de procesos históricos de polarización regional: el caso de la región Puebla-Tlaxcala. Revista bibliográfica de geografía y ciencias sociales (Serie documental de Geo Crítica) Vol. XI, nº 676.

34 González Gutiérrez, Darío. 2006. La industrialización como detonante ...

35 Aguilar-Robledo Miguel. 1998. Haciendas y condueñazgos en la Huasteca potosina. En: nuevos aportes al conocimiento de la Huasteca. Centro de Investigaciones y Estudios Superiores en Antropología Social CIESAS, México 388 pp.,

Y Bazant, Jan. 1995. Cinco haciendas mexicanas en tres siglos de vida rural en SLP. (1600-1910). El Colegio de México 3 ed. 231 pp, Crespo, Horacio. 1988. Historia del azúcar en México....

36 Barthas, Brigitte.1996. Ajuste estructural y recomposición de la agricultura regional En: estudios de la agricultura mexicana. no. 24-25, 99-105 pp.

37 Escobar, Antonio y Fagoaga, Ricardo. 2005. Indígenas y comercio en las Huastecas (México), siglo XVIII. Centro de investigaciones y estudios superiores en antropología social, d. f. Universidad de California-San Diego HMEX, lv: 2, 333-417 pp. Aguilar-Robledo Miguel. 1998. Haciendas y condueñazgos en la Huasteca potosina. En: nuevos aportes al conocimiento de la Huasteca. Centro de Investigaciones y Estudios Superiores en Antropología Social CIESAS, México 388 pp. y Barthas, Brigitte. 1997. De la selva al naranjal (transformaciones de la agricultura indígena en la Huasteca potosina) en revista de geografía agrícola 183-198 pp.

38 Sánchez, Ernest. 2001. Azúcar y poder...

39 Santamaría García Antonio. 2005. Azúcar en América. Revista de Indias. Vol. LXV, núm. 233 9-32 pp.

40 Del Valle Pavón, Gdelv. 2003. Historia financiera de la Nueva España en el siglo XVIII y principios del XIX, una revisión crítica. HMex, LII: 3, 649-675 pp y Ortega, Martha.1999. "Colonización de Alta California, primeros asentamientos españoles". Signos Históricos año 1 Vol. 001, 85-113 pp.

41 Escobar, Antonio y Fagoaga, Ricardo. 2005. Indígenas y comercio en ... y Del Valle Pavón, Gdelv. 2001. Antagonismo entre el consulado de México y el virrey Revillagigedo por la apertura comercial de Nueva España, 1789-1794. EHN 24, enero-junio, 111-137 p.

42 Sánchez, Ernest. 2001. Azúcar y poder...

43 Escobar, Antonio y Fagoaga, Ricardo. 2005. Indígenas y comercio en ...

44 Mintz, Sidney. 1996. Dulzura y poder, el lugar del ...

45 Sharrer, Tamm. 1999. Fuentes para el estudio de la tecnología azucarera siglos XVII y XVIII. ALHE. no. 11 enero-junio 25-28 pp.

46 Escobar, Antonio y Fagoaga, Ricardo. 2005. Indigenas y comercio en ...

47 Crespo, Horacio. 1988. Historia del azúcar en México.... y Landázuru, Gisela y Vázquez, Verónica. 1988. Azúcar y Estado 1750-1880, México, DF, FCE, 355 pp.

48 Escobar Ohmstede, Antonio y Gordillo, Jaqueline. 2001. En pos de la construcción de una unidad política de una región en México: Las Huastecas en la primera mitad del siglo XIX. European Review of Latin American and Caribbean Studies 71, October 47-69 pp.

49 Sánchez, Ernest. 2007. Las incertidumbres del cambio: redes sociales y mercantiles de los hacendados-comerciantes azucareros del centro de méxico (1800-1834). Instituto de Investigaciones Dr. José María Luis Mora HMex, LVI: 3, 919-968 pp. y Corbett, Barbara. 1989. Soberanía, elite política... 


\section{BIBLIOGRAFÍA}

ABELLO VIVES A., E. Bassi A. (2006). Un Caribe por fuera de la ruta de la Plantación, Memorias de la cátedra del Caribe Colombiano. San Andrés: Universidad Nacional de Colombia (sede Caribe) - Revista No 35 Observatorio del Caribe Colombiano, 191 pp. En: http://www.ocaribe. org/downloads/catedra_virtual/articulo_abellobassi.pdf A

BARTHAS B. (1997). De la selva al naranjal (transformaciones de la agricultura indígena en la Huasteca potosina) en revista de geografía agrícola 183-198 pp.

BARTHAS B. (1996). Ajuste estructural y recomposición de la agricultura regional En: estudios de la agricultura mexicana. no. 24-25, 99-105 pp.

BAZANT J. (1995). Cinco haciendas mexicanas en tres siglos de vida rural en SLP. (1600-1910). El Colegio de México 3 ed. 231 pp.

CORBETT B.M. (1989). Soberanía, elite política y espacios regionales en San Luis Potosí (18241828) Secuencia No. 15, septiembre-diciembre 7-27 pp.

CRESPO H., (1988). Historia del azúcar en México. Fondo de Cultura Económica 2 Tomos 2da edición México D.F, 1029 pp.

DEL VALLE PAVÓN, G., (2003). Historia financiera de la Nueva España en el siglo XVIII y principios del XIX, una revisión crítica. HMex, LII: 3, 649-675 pp.

DEL VALLE PAVÓN, G., (2001). Antagonismo entre el consulado de México y el virrey Revillagigedo por la apertura comercial de Nueva España, 1789-1794. EHN 24, enero-junio, 111-137 p.

ESCOBAR OHMSTEDE A, R. A. Fagoaga H., (2005). Indígenas y comercio en las Huastecas (México), siglo XVIII. Centro de investigaciones y estudios superiores en antropología social, d. f. Universidad de California-San Diego HMEX, lv: 2, 333-417 pp.

ESCOBAR OHMSTEDE A., J. Gordillo. (2001). En pos de la construcción de una unidad política de una región en México: Las Huastecas en la primera mitad del siglo XIX. European Review of Latin American and Caribbean Studies 71, October 47-69 pp.

GONZÁLEZ GUTIÉRREZ D. (2006). La industrialización como detonante de procesos históricos de polarización regional: el caso de la región Puebla-Tlaxcala Revista bibliográfica de geografía y ciencias sociales (Serie documental de Geo Crítica) Universidad de Barcelona, Vol. XI, nº 676.

LANDÁZURU B., G y V. Vázquez M., (1988) Azúcar y Estado 1750-1880, México, DF, FCE, $355 \mathrm{pp}$.

MINTZ S.W. (1996). Dulzura y poder, el lugar del azúcar en la historia moderna. Siglo XXI editores México D.F. 299 pp. 
MOCTEZUMA P.Y. (2006). Los teenek productores de piloncillo. Revista Relaciones No. 106, edición primavera Vol. XXVII, 153-182 pp.

ORTEGA S.M. Colonización de Alta California, primeros asentamientos españoles. Signos Historicos año 1 Vol. 001, 85-113 pp.

RAMOS G.O.R., (2006). Caña de azúcar en Colombia. Revista de Indias, 2005, vol. LXV, núm. 233 49-78 pp.

RUVALCABA M. J. (1996). Vacas, mulas, azúcar y café; los efectos de su introducción en la huasteca, México CIESAS.

SÁNCHEZ SANTIRÓ E. 2007. Las incertidumbres del cambio: redes sociales y mercantiles de los hacendados-comerciantes azucareros del centro de méxico (1800-1834) Instituto de Investigaciones Dr. José María Luis Mora HMex, LVI: 3, 919-968 pp.

SÁNCHEZ SANTIRÓ E. (2001). Azúcar y poder. Editorial Praxis Cuernavaca México 331 pp

SHARRER T. B. (1999). Fuentes para el estudio de la tecnología azucarera siglos XVII y XVIII. ALHE. no. 11 enero-junio 25-28 pp.

VIÑA BRITO A., (2006). The Social Organization of Work in Sugar Mills of the Canary Islands (15th-16th centuries) En la España Medieval No. 29 359-381 pp.

VON WOBESER G, 1987. La política económica de la corona española frente a la industria azucarera en la Nueva España, 1599-1630, Estudios de Historia Novohispana, Universidad Nacional Autónoma de México. Instituto de Investigaciones Históricas, Volumen 9, 51-66 pp 